\title{
The Cedars of Lebanon, the Limits of Restoration, and Cultural Loss
}

Steven N. Handel

Open thy doors, O Lebanon, that the fire may devour thy cedars. Howl, fir tree; for the cedar is fallen; because the mighty are spoiled.

\section{Moving Climate Zones, North and Up}

Our restoration work is forged on a moving anvil. We analyze and plan for success in today's landscape, but physical and biotic changes are rapidly approaching and erode the assumptions that underlie our efforts. As climate change warms our lands and the seas, the species mixes of past habitats that we emulate will be inappropriate for future conditions. Very often species can disperse north to a latitude that fits their physiological requirements. But different species move at different rates, and successful biotic communities of the future may never fully resemble the templates upon which we base our work.

For communities on mountainsides, the migration is often upslope, not towards the pole, as propagules and animal dispersers find cooler microsites at higher elevations. As species on mountains march towards the summit, they may reach the end of migratory hope when the top is reached, and no cooler microsites exist above. The coldadapted species decline and those adapted to warmth increase, a process that has been called "thermophilization," a word as alien as the ecology it describes. These high mountain habitats and their species have literally no place to go and will disappear from the local biodiversity. No restoration plan or action can make a favorable habitat above the mountain's summit, and our Alpine and subalpine floras will have an absence of sustainable room. The constraint for restoration will be thin air, the converse of substrate.

\section{Running out of Mountain: The Cedars of Lebanon}

Cedars of Lebanon (Cedrus libani) are icons for this sad limit to restoration practice. Hulking, horizontal, historic, these trees have been mentioned in western literature

Ecological Restoration Vol. 36, No. 4, 2018

ISSN 1522-4740 E-ISSN 1543-4079

(C)2018 by the Board of Regents of the University of Wisconsin System. for thousands of years. Cut and shipped throughout the classical world, they were used for Egyptian palaces and King Solomon's temple, then more prosaically for railroad construction and firewood during colonial regimes. Forest fragments remain and are treasured by diverse members of Lebanese civil society. Some stands are UNESCO World Heritage sites, such as the Forest of the Cedars of God. Take a bow.

The danger now is temperature rise, not overharvesting for architectural demand. The existing stands are fragmented along the mountain ridges above Beirut, and suffer the well-documented physical and biotic stresses of edge effects, as well as threats from adjacent human land-use and invasive species. Warming climate would normally favor population range movement up or north, but conflicting agricultural pressures and lack of higher altitudinal areas slow migration. The race is birth rate of seedlings versus death rate of adults, with new insect pests increasing the latter as a grim partner to temperature regime stress itself.

\section{Culture as an Ecological Service}

The value of cedar wood is complemented by the status of Cedrus libani as a symbol of the country's glorious past. We remember Beirut's tagline as "the Paris of the Middle East," where one could walk a Mediterranean beach in the morning, lunch at a downtown café, then ski in the mountains in the afternoon. What followed were decades of civil war and foreign military adventures that gave Lebanon a low position on the international tourist list. But there was always the Cedar of Lebanon image, gracing the national flag and coinage, a botanical symbol of the good old days, when diverse human communities made structures for tolerance.

A horticultural gem that is enjoyed throughout temperate landscapes and botanic gardens for its stylish profile and its biblical starring role, the tree grew into a national touchstone for a hopeful future. Mature trees remained here and there on the mountainsides while civic institutions and government officials were crushed. We often 
value other canopy trees for their many ecological services and habitat-defining structure, but the Cedar of Lebanon symbol became more important in culture than as the "mere" ecological functions and economic value of the living tree. In North America we have coast redwoods, sugar maples, and live oaks to define local geographies and cultures, but none of these reach the heights of a national symbol as does $C$. libani.

Do we each have our own Cedars of Lebanon? We may all have our local restoration dreamscapes that will fade away with the climate changes that are upon us. Is it the tallgrass prairie that despite years of hard-won restoration knowledge and careful work, much it reported in this journal, is becoming more difficult to secure? Drier and hotter microclimates and more frequent fires challenge grassland reproductive rates and leave available space for tolerant, albeit non-native, weed species. Is it the forests, chaparral, and sage brush of the active western chapters of SER, now burning at historically high rates and areas, weakening the ability of natural and human-managed new recruitment of once abundant species to keep pace? Is it your Gulf Coast coastal salt-tolerant vegetation, inundated over and over by recurrent storm surges and sea level rise intrusions, pushing these valuable halophytes inland? That inland is often paved and populated, with no space for the retreating coastal plants to reestablish; the migration is more like falling into the maw of urbanization. Maybe it is efforts to restore and secure the sugar maple stands of New England, as we furtively glance at the U.S. Forest Service's tree migration studies, showing that the eastern forest species are moving up to Canada, like the political refugees of earlier decades. Are these the Cedars of Lebanon of our Down East colleagues?
Our landscapes define our regions and our lives within them. The past is not prologue in our restoration work, we know. The loss of memories of our biological culture, analogue of Lebanon's cedars, may bite more painfully than the diminishing ecological functions that we mourn over in our presentations to the public.

\section{Recommended Readings}

Beals, E.W. 1965. The remnant cedar forests of Lebanon. Journal of Ecology 53:679-694.

Chaney, W.R. and M. Basbous. 1978. The cedars of Lebanon: witnesses of history. Economic Botany 32:118-123.

Chen, I.C., J.K. Hill, R. Ohlemüller, D.B. Roy, and C.D. Thomas. 2011. Rapid range shifts of species associated with high levels of climate warming. Science 333:1024-1026.

Dullinger, S., A. Gattringer, W. Thuiller, D. Moser, N.E. Zimmermann, A. Guisan, et al. 2012. Extinction debt of high-mountain plants under twenty-first-century climate change. Nature Climate Change 2:619.

Gottfried, M., H. Pauli, A. Futschik, M. Akhalkatsi, P. Barančok, J.L.B. Alonso, et al. 2012. Continent-wide response of mountain vegetation to climate change. Nature Climate Change 2:111.

Hall, C.M., M. James and T. Baird. 2011. Forests and trees as charismatic mega-flora: implications for heritage tourism and conservation. Journal of Heritage Tourism 6:309-323.

Handel, S.N. 2012. The Red Queens of restoration. Ecological Restoration 30:3-4.

Pauli, H., M. Gottfried, S. Dullinger, O. Abdaladze, M. Akhalkatsi, J.L.B. Alonso, et al. 2012. Recent plant diversity changes on Europe's mountain summits. Science 336:353-355.

Samuels, K.L., 2017. Biodiversity in World Heritage Cultural Landscapes: possibilities and problems for communicating climate change and mobilizing mitigation. Culture, Agriculture, Food and Environment 39:116-126.

Shackley, M. 2004. Managing the cedars of Lebanon: botanical gardens or living forests? Current Issues in Tourism 7:417-425.

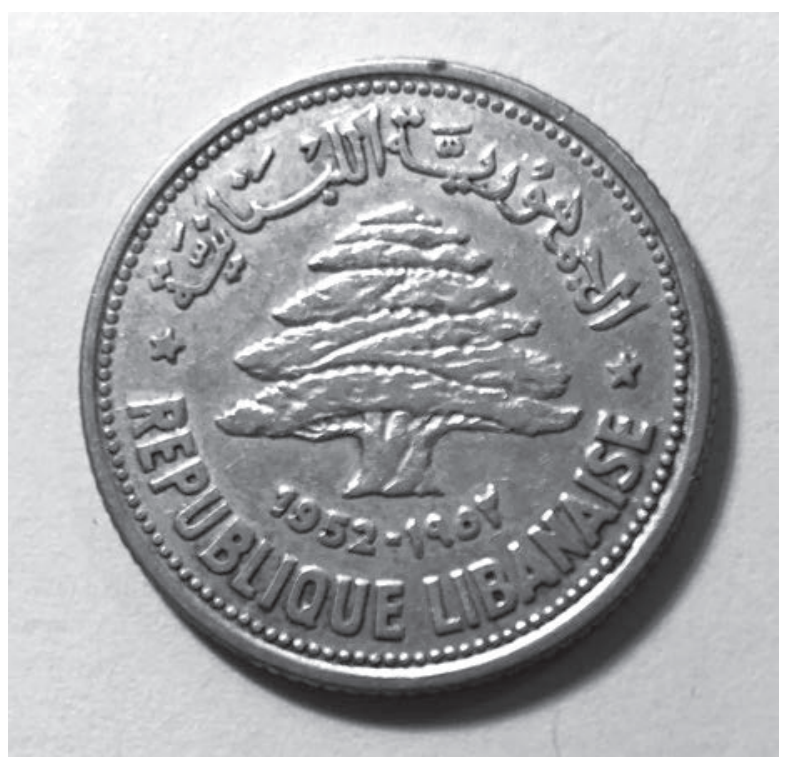

Lebanese coin. Photo credit: Steven N. Handel. 